\title{
Study on the deformation and damage characteristics and optimization of support parameter of shallow coal seam roadway
}

\author{
Zhenxiong Yan \\ School of Resource and Safety Engineering \\ China University of Mining and Technology \\ Beijing, China \\ 785484010@qq.com
}

\section{Boyang Qiao}

School of Resource and Safety Engineering China University of Mining and Technology

Beijing, China

370921139@qq.com

\author{
Lili Shao \\ School of Resource and Safety Engineering \\ China University of Mining and Technology \\ Beijing, China \\ 280638417@qq.com
}

\section{Qiwei $\mathrm{Yu}$}

School of Resource and Safety Engineering China University of Mining and Technology

Beijing, China

419719844@qq.com

\begin{abstract}
Taking the 12108 working face 3-1 coal seam in Lijiahao coal mine as the engineering background, comprehensively applying roof borehole observation, multi-base point displacement monitoring, measuring the range of loose damage of surrounding rock and other measurements to get in-depth knowledge of the characteristics of surrounding rock damage of roadway, on this basis, put forward four kinds of optimization of roadway support scheme. Through applying the calculation method of numerical simulation and taking the economic efficiency into account, provide the optimized support scheme for the roadway which is affected by first mining activity and second mining activity respectively. Provide the basis for support parameter choosing in shallow buried thin bedrock roadway.
\end{abstract}

Keyword-shallow buried; mining roadway; support parameter; numerical simulation

\section{INTRODUCTION}

There is abundant of coal resources in the western region of China, and the coal reserves in Xinjiang, Inner-Mongolia, Shanxi and Shaanxi province account for $81.3 \%$ of the total amount. In order to fulfill the national development strategy, there have been large scale mining activities in Inner-Mongolia ${ }^{[1-4]}$. Most of the excavated coal seams are covered by thin bedrock. The upper rock strata consist of thick aeolian accumulated sand seam, and the bedrock is relatively thin. It belongs to typical thin bedrock coal seam. Besides, the intensity of mining activities and the double roadways layout of backstopping roadways, half of the roadways are affected twice by mining activities. Especially in the condition of thin bedrock and muddy rock roof, this kind of influence appeared more severe. The deformation of roof was not so large during backstopping period, but there was several roof caving accidents. The accidents mostly occurred in the roadways alongside the working face. Therefore, studying the support problem in the roadways under thick aeolian accumulated sandstone and thin bedrock is of great significance for promoting the safety and high-efficiency in Lijiahao coal mine as well as the carrying out of Western Development ${ }^{[5-7]}$.

This paper takes 3-1coal seam in Lijiahao coal mine as the engineering background. On the basis of detail information of the characteristics of surrounding rock deformation, apply the numerical simulation method to study the deformation characteristics under different support schemes. And optimize the support parameters for the roadways which are affected by first and second mining. The study result plays an instructive role in the design of support scheme and maintenance for backstopping roadways in thin bedrock coal seam and provides reliable basic statistics and technical support ${ }^{[8-10]}$.

\section{OVERVIEW}

Lijiahao coal mine is located in Southeastern Dongsheng District Erdos City Inner-Mongolia. The shape of the coal field is a polygon with the length from south to north of about $9 \mathrm{~km}$ and from east to west of about $8 \mathrm{~km}$ and the area is about $67.65 \mathrm{~km} 2$. There are 8 minable coal seams in the coal field. The depth of these coal seams lies from 100 400m. The average gap between each coal seam lies from $4 \sim 40 \mathrm{~m}$. The depth of 3-1 coal seam is about $200 \mathrm{~m}$, and lies in the upper part of 3 coal seam group. The whole area is minable with the minable thickness from $0.8 \sim 7.05 \mathrm{~m}$ and average thickness of $3.86 \mathrm{~m}$. The main characteristics of this coal seam are shallow buried, thin bedrock, the group mostly covered by thick aeolian accumulated sand seam, low gas, of simple geological structure and easy to excavate.

12108 working face is located in $3-1$ coal seam. The net section of air return roadway for the working face is $5.5 \mathrm{~m} \times 3.3 \mathrm{~m}$. The support for the roadway is bolting with wire mesh. The material and parameters of the support are as following:

Roof bolt: $\varphi 20 \times 2500 \mathrm{~mm}$ left-hand screw thread steel; 
Roof anchor cable: $\varphi 17.8 \times 6500 \mathrm{~mm}$;

Positive side: $\varphi 20 \times 2000 \mathrm{~mm}$ FRP bolt;

Left wall: $\varphi 16 \times 2000 \mathrm{~mm}$ round steel bolt.

\section{CHARACTERISTICS OF SURROUNDING ROCK DEFORMATION AND FAILURE}

To understand the occurrence state and the extent of damage of the roadway roof surrounding rock, do several groups borehole observation in different locations of 12108 air return roadway. Through a comprehensive analysis of the observation results, obtained: roof surrounding rock is mainly sandy mudstone and coal, some sections contain grained sandstone, where coal seam is relatively thin, mostly located between the sandy mudstone; some sections consist a small amount of exposed coal; there are more coal line and intercalary strata in sandy mudstone; roof surrounding rock lithology changes little; although thickness of top coal have some ups and downs, distribution of rock strata are basically identical and regular; affected by mining near the face, the development of fragmentation degree and fracture degree of roadway roof structure are of different levels, mainly concentrate in the range of $0 \sim 3 \mathrm{~m}$, and shallow $(0 \sim 1 \mathrm{~m})$ surrounding rock is mainly fractured; fracture density decreases with the depth grows, and some sections occurs apparent separation. Some of the observation results are as Fig .1
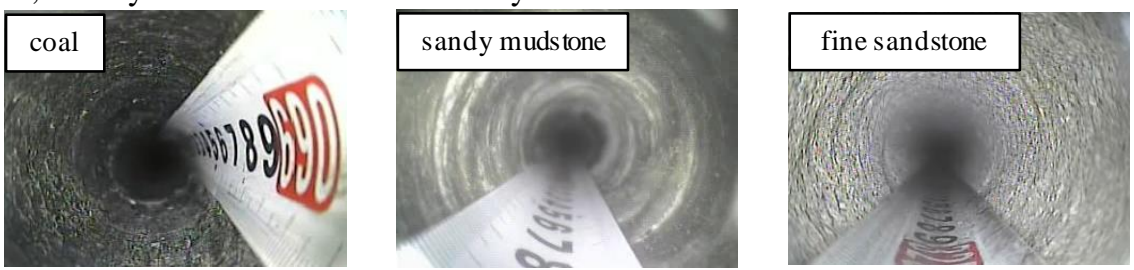

Figure 1. Result of roof structure observation

In order to understand the deformation of roadway surrounding rock accurately, apply the multi-point displacement roof monitor ${ }^{[9]}$ as monitoring tool. On the basis of the characteristics of roadway surrounding rock and current production situation, distribute 5 groups of observation station to observe the deformation and fracture situation in roadway roof. The result of NO. 2 observation station is shown in Fig .2. From the results, in the existing supporting conditions, the deformation amount in first mining period can be controlled effectively; the initial phase of monitoring, deformation rate of roadway surrounding rock is low; in the period of affected by mining in nearby working face, the deformation of the surrounding rock increases sharply and decreases gently with the working face advancing and the affect from mining weakening, and the deformation rate of each rock strata can basically be controlled; the separation in $1 \sim 3 \mathrm{~m}$ strata is the largest while in $0 \sim 1 \mathrm{~m}$ and $6 \sim 8 \mathrm{~m}$ sections the separation is relatively small, and the roof failure area mainly occurs in shallow surrounding rock from the range of $1 \sim 3 \mathrm{~m}$. At the same time, from the result of loose failure test in surrounding rock, as is shown in Fig .3, obtained: the range of deformation in the two side of roadway lies in $0.9 \sim 1.6 \mathrm{~m}$, and it is relatively small; the deformation degrees in both walls of the roadway are relatively equivalent.

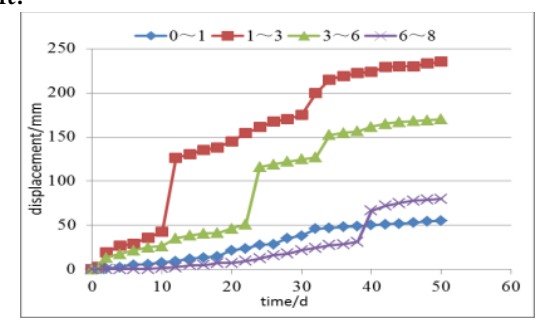

Figure 2. Result of NO. 2 observation station

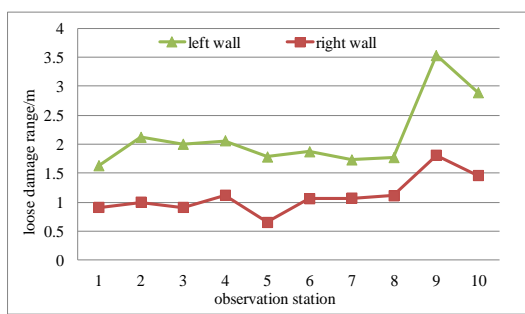

Figure 3. Result of loose failure test

\section{NUMERICAL SIMULATION ANALYSIS}

\section{A. The establishment of the model}

To reasonably optimize the backstopping roadway support parameter in Lijiahao coal mine, on the basis of the specific geological conditions of surrounding rock, deformation characteristics and field production, chose different supporting schemes to simulate the plastic deformation range and rules of surrounding rock which is affected by first and second mining activities. In this paper, by using the finite difference numerical calculation program, established a numerical model with the width of $295 \mathrm{~m}$, height of $40 \mathrm{~m}$ and thickness of $50 \mathrm{~m}$, and applied Mohr-Coulomb Criteria which is based on the elastic-plastic criteria in the model.

According to the deformation characteristics of roadway in site and aiming at the problem of existing supporting scheme, put forward the following four kinds of optimization scheme:

Supporting scheme 1:

Roof support parameters: specifications for the left-hand screw thread steel bolt: $\Phi 20 \mathrm{~mm} \times 2400 \mathrm{~mm}, 6$ in each row, row spacing is $1 \mathrm{~m}$; specifications for the anchor wire: $\Phi 17.8 \mathrm{~mm} \times 7000 \mathrm{~mm}, 2$ in each row, row spacing is $2 \mathrm{~m}$; right wall used $\Phi 18 \times 2000 \mathrm{~mm}$ FRP bolt; left wall used $\Phi 16 \times 2000 \mathrm{~mm}$ round steel bolt.

Supporting scheme 2:

Roof support parameters: Specifications for the left-hand screw thread steel bolt: $\Phi 20 \mathrm{~mm} \times 2200 \mathrm{~mm}, 6$ in each row, row spacing is $1 \mathrm{~m}$; specifications for the anchor 
wire: $\Phi 17.8 \mathrm{~mm} \times 6500 \mathrm{~mm}, 2$ in each row, row spacing is $3 \mathrm{~m}$; roadway bolting parameters: right wall used $\Phi 18 \times 2000 \mathrm{~mm}$ FRP bolt; left wall used $\Phi 16 \times 2000 \mathrm{~mm}$ round steel bolt.

Supporting scheme 3:

Roof support parameters: specifications for the left-hand screw thread steel bolt: $\Phi 20 \mathrm{~mm} \times 2200 \mathrm{~mm}, 6$ in each row, row spacing is $1 \mathrm{~m}$; specifications for the anchor wire: $\Phi 17.8 \mathrm{~mm} \times 6500 \mathrm{~mm}, 2$ in each row, row spacing is $2 \mathrm{~m}$; roadway bolting parameters: right wall used $\Phi 18 \times 2100 \mathrm{~mm}$ FRP bolt; left wall used $\Phi 18 \times 2100 \mathrm{~mm}$ round steel bolt.

Supporting scheme 4:

Roof support parameters: specifications for the left-hand screw thread steel bolt: $\Phi 20 \mathrm{~mm} \times 2400 \mathrm{~mm}, 6$ in each row, row spacing is $0.9 \mathrm{~m}$; specifications for the anchor wire: $\Phi 21.6 \mathrm{~mm} \times 7000 \mathrm{~mm}, 2$ in each row, row spacing is $2 \mathrm{~m}$; roadway bolting parameters: right wall used $\Phi 18 \times 2100 \mathrm{~mm}$ FRP bolt; left wall used $\Phi 18 \times 2100 \mathrm{~mm}$ round steel bolt.

\section{B. The Result Analysis}

1) Analysis of plastic damage in roadway
surrounding rock

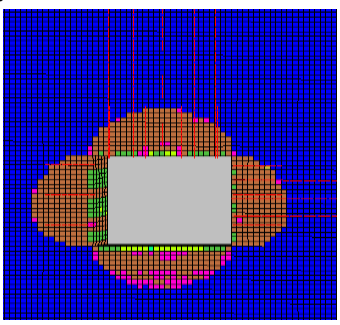

Figure 4. Plastic zone in main transport roadway under first mining influence (scheme 1)

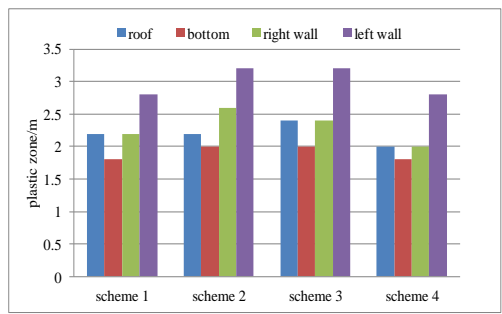

Figure 5. Damage zone of surrounding rock in main transport roadway under first mining influence

Fig .7 shows numerical simulation result of the area $10 \mathrm{~m}$ ahead working face in the assistant transport roadway under second mining influence. Through the comparison with the situation of first mining influence, it shows that the plastic damage zone in surrounding rock increases significantly and the plastic damage zone evolves to an irregular semi-ellipse when developing to deeper area. The damage zone in surrounding rock of scheme 1 and 2 is the largest, and the damage depth in roof can reach $4.6 \mathrm{~m}$, two walls $2.2 \mathrm{~m}$. However, the damage zone in bottom is relatively small. The damage
Fig .5 and Fig .6 show numerical simulation result of the area $10 \mathrm{~m}$ ahead working face in the roadway under first mining influence. Fig .4 shows numerical simulation result of main transport roadway applying support scheme 1 under first mining influence. The plastic zone in roof and bottom under the four support schemes presented like a semi-ellipse. The range of plastic damage zone did not extend $2.7 \mathrm{~m}$. Besides, the damage depth of roof is slightly larger than the two walls. In the four schemes, the damage depth in surrounding rock of scheme 2 is the largest, but the damage still lies in the control range of the bolt (anchor wire). The damage depth in surrounding rock of scheme 4 is the smallest, but the numerical simulation result shows little difference with scheme 2. From numerical calculation result in assistant transport roadway, it shows that the plastic zone in roof and bottom also presents like a semi-ellipse. Due to the position difference of the two roadways, the degrees of influence caused by mining activities are different. When under the same support scheme, the plastic zone in assistant transport roadway is smaller than that in main transport roadway. Besides, among these four schemes, the damage range and characteristics of surrounding rock is similar to the situation in main transport roadways

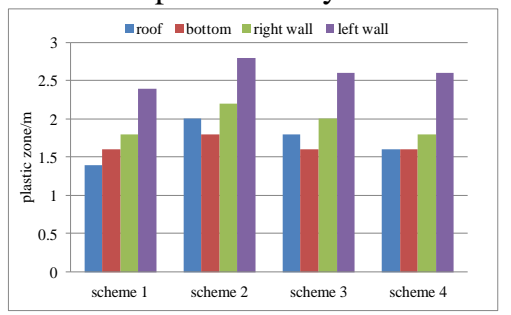

Figure 6. Damage zone of surrounding rock in assistant transport roadway under first mining influence

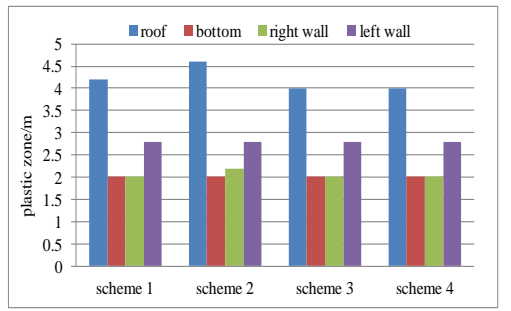

Figure 7. Damage zone of surrounding rock in assistant transport roadway under second mining influence

zone in surrounding rock of scheme 3 and 4 is relatively small, but the damage depth in roof can reach $3.6 \mathrm{~m}$, which has already extended the control range of the bolt. But the plastic damage in two walls and bottom is not significant.

2) Analysis of result of roadway surrounding rock deformation

Fig .8 and Fig .9 show numerical simulation result of surrounding rock displacement in roof and two walls $10 \mathrm{~m}$ 


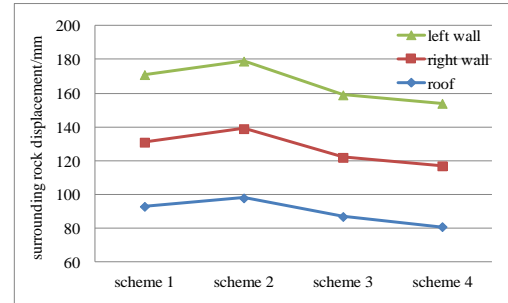

Figure 8. Displacement of surrounding rock in main transport roadway under first mining influence

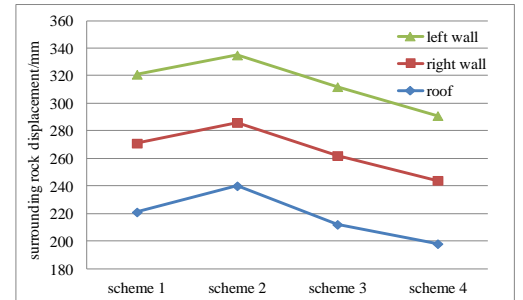

Figure 9. Displacement of surrounding rock in assistant transport roadway under first mining influence

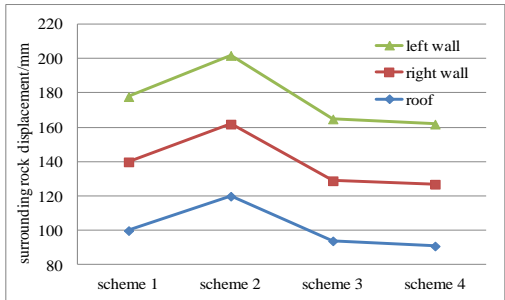

Figure 10. Displacement of surrounding rock in assistant transport roadway under second mining influence ahead working face in the roadway under first mining influence. It is obvious that during the first mining influence period four support schemes all achieve good result in controlling the deformation of surrounding rock. The maximum displacement in main transport roadway is $120 \mathrm{~mm}$ and $98 \mathrm{~mm}$ in assistant transport roadway. Besides, the displacement in two walls is far smaller than that in roof. All the four support schemes can appeal to the need of production. From the result in Fig .10, it shows that, affected by the second mining influence, the displacement of surrounding rock increased sharply in assistant transport roadway roof. Among these four schemes, the maximum displacement reaches $240 \mathrm{~mm}$. Comparatively, the displacement in walls is not so large.

\section{Determination of the support scheme}

The numerical simulation result shows that, from the surrounding rock plastic zone and roadway displacement, in first mining influence period, the damage depth and displacement in surrounding rock of scheme 4 is the smallest and scheme 2 the largest. But the damage situation of the two schemes both can be controlled by the support and achieve the need of safe production. However, from the aspect of economic efficiency, scheme 2 shows great advantage compared with scheme 4. So, take scheme 2 as the support scheme to optimize the support parameters. When the roadway is influenced by second mining, the damage zone and displacement in roadways of the four schemes all increase significantly, but still in the control range of anchor wire. Taking the in-site engineering situation and support cost into consideration, take scheme 3 as the support scheme to optimize the support parameters.

\section{V.CONCLUSION}

(1) Through the survey result in site, the most component in rood surrounding rock is sandy mudstone and coal; the lithology of roof surrounding rock does not vary much and is relatively regular; under first mining influence, the deformation in surrounding rock main lies in the range of $0 \sim 3 \mathrm{~m}$; the loose damage range lies in
$0.9 \sim 1.6 \mathrm{~m}$

(2) According to the survey result in site and existing supporting problems, put forward four optimization schemes; through numerical simulation, taking all the factors into consideration, take scheme 2 as the support scheme to optimize the support parameters for roadways under first mining influence and take scheme 3 as the support scheme to optimize the support parameters for roadways under second mining influence.

\section{REFERENCE}

[1] Study on Coal Development and Environmental Protection Strategy[A].China Coal Economy Research(2005 2008)(2)[C].:,2009:60.

[2] Zhang Chun, et al.. Bolt Support Parameters Optimization for Shallow-buried Easily-weathering backstopping roadway [J].Mining Safety and Environmental Protection, 2011, 02 :24-27.

[3] GAO Tianming, et al. The Inequality of China's Coal Resources and Its Flow Paths [J]. Journal of Natural Resources,2013,01:92-103.

[4] Yin Dewei, Yin Qian, Kong Lingchang. Research on Optimization Mechanism of Roadway Stability With Large Cross Section and Shallow Buried [J].Safety in Coal Mines,2013,10:56-58+62.

[5] LIAO Jinglong, et al. Roof Fall Accidents Analysis and Support Countermeasure in Large Section Bedded Roof Roadway[J]. Safety in Coal Mines, 2012, 10: 195-197.

[6] Xu Xiaobing. Research on Deformation Mechanism and Control Technology of Mining Gateway in Shallow Buried Closed Distance Seam Group [D].Xi'an University of Science and Technology,2012.

[7] WANG Bing, Coal Roadway Anchor Bolt Support Failure Roof Fall Reason Analysis [J].Coal and Chemical Industry, 2014, 11:118-120.

[8] Shang Bo, Du Xiaojie. Study on Compound Roof Support Parameters Optimization [J].Coal and Chemical Industry, 2014, $06: 1-3$.

[9] Jia Housheng, et al.. Design and Application of Multi Point Roof Separation Monitor to Mine Gateway [J].Coal Engineering, 2012, 09: 110-113.

[10] Cao Xie, et al. Research on Laws of Strata Behaviors and Optimization of Supporting Parameters in Roadway [J].Coal Science and Technology, 2014, S1 :58-60. 